\title{
JUSTIÇA ESPACIAL E CIDADE DIGITAL: ESPAÇO COMO MEIO OPERACIONAL NO BRASIL ${ }^{1}$
}

\author{
SPATIAL JUSTICE AND THE DIGITAL CITY: SPACE \\ AS AN OPERATIONAL MEDIUM IN BRAZIL \\ JUSTICIA ESPACIAL Y CIUDAD DIGITAL: ESPACIO \\ COMO MEDIO OPERACIONAL EN BRASIL \\ Angelo Serpa - Universidade Federal da Bahia - Salvador - Bahia - Brasil \\ angserpa@ufba.br
}

\begin{abstract}
Resumo
Busca-se, com o presente artigo, construir uma abordagem comparativa da inserção de tecnologias de informação e comunicação no território nacional, em diferentes escalas (macrorregional, estadual e intraurbana), pensando o espaço como "meio operacional" e tomando as noções de justiça espacial e acessibilidade como princípios norteadores da reflexão proposta. A discussão está também baseada na assertiva de que os lugares são "plataformas" para a construção de ações e discursos de cunho eminentemente espacial que atravessam variados recortes e escalas.

Palavras-chave: Justiça espacial, cidade digital, espaço, meio operacional.
\end{abstract}

\section{Abstract}

The intention is to present a comparative picture of the insertion of information and communication technologies in the national territory, on different scales (macro-regional, provincial and intra-urban), thinking of space as an operational medium and taking the notions of spatial justice and accessibility as the guiding principles of the proposed reflection. The discussion is also based on the assumption that places are "platforms" for the construction of actions and speeches of an eminently space matrix that goes through varied scales and cuttings.

Keywords: Spatial justice, digital city, Space, operational medium, place.

\section{Resumen}

Con el presente artículo se busca construir un enfoque comparativo de la inserción de tecnologías de información y comunicación en el territorio nacional, en diferentes escalas (macrorregional, estatal e intraurbana), pensando el espacio como "medio operacional" y tomando nociones de justicia espacial y accesibilidad como principios norteadores de la reflexión propuesta. La discusión también se basa en la asertiva de que los lugares son "plataformas" para la construcción de acciones y discursos de carácter eminentemente espacial que atraviesan diversos recortes y escalas.

Palabras clave: Justicia espacial, ciudad digital, espacio, medio operacional.

\section{Introdução - 0s lugares como "meio operacional"}

A heterogeneidade da difusão das técnicas e dos objetos técnicos resulta do modo desigual como eles vão se inserir no tempo e no espaço - na história e no território. Para Milton Santos (1996), as técnicas e os 
objetos técnicos precisam sempre ser analisados em conjunto com seu entorno, já que o espaço preexistente vai incorporá-los de modo particular nos respectivos lugares de ocorrência.

Assim, sob uma perspectiva geográfica, as técnicas e os objetos técnicos seriam redefinidos pelo espaço, que os incluiria em um "conjunto coerente" através da contiguidade espacial, exigindo também ações solidárias e coletivas para seu funcionamento. Um enfoque geográfico das técnicas vai pressupor, portanto, uma reflexão de como os objetos técnicos se contextualizam em um dado lugar e de como as ações humanas se realizam nesse substrato (Santos, 1996).

Milton Santos (1996) vai enfatizar, no contexto do processo atual de globalização, que a desejada homogeneização do espaço por parte das grandes organizações e a partir de uma tecnologia "cegamente utilizada" se revela como uma impossibilidade, devido à realidade e aos constrangimentos espaciais presentes nos diferentes territórios (e lugares).

As técnicas influenciam o modo como percebemos o espaço e o tempo, não só por sua existência física, mas também pela maneira como afetam nossas sensações e nosso imaginário. Por outro lado, os lugares vão se relacionar de modo diferenciado com as técnicas e os objetos técnicos, de acordo com as condições que oferecem enquanto "meio operacional", para viabilizar a produção, a circulação, a comunicação, o lazer etc.

Mas, se o espaço é passível de uma avaliação objetiva, como "meio operacional", enquanto "meio percebido" (e aqui, poderíamos acrescentar, como "meio concebido") vai exigir uma avaliação de cunho subjetivo: "na realidade, o que há são invasões recíprocas entre o operacional e o percebido. Ambos têm a técnica como origem e por essa via nossa avaliação acaba por ser uma síntese entre o objetivo e o subjetivo" (Santos, 1996, p. 45).

A proposta de Santos pode ser desdobrada para compreensão das técnicas como produtoras de articulação / contatos / encontro e / ou isolamento / segregação, algo especialmente instigante na análise dos meios de comunicação e de sua apropriação socioespacial nos diferentes lugares do mundo, assim como para a explicitação das desigualdades existentes nos diferentes recortes espaciais quanto à inserção e ao acesso das/ às tecnologias de informação e comunicação.

As mídias diferem dos meios mais "tradicionais" de comunicação por uma maior capacidade de memorizar informações, assim como pelo modo de processá-las e os suportes necessários para o estabelecimento 
do processo de comunicação. O que chamamos revolução das mídias resulta, sobretudo, do desenvolvimento de novas técnicas e de novos objetos técnicos (Claval, 2003).

Essa revolução dos meios de comunicação se dá, no entanto, em convivência (pacífica ou não) com os meios e modos mais tradicionais. $\mathrm{O}$ que muda é a velocidade com que as informações passam a ser trocadas, encurtando distâncias entre os lugares do mundo contemporâneo e possibilitando o intercâmbio de uma quantidade muito maior de imagens, sons e textos do que em passado relativamente recente.

Entre 1500 e 1900, a evolução do universo da comunicação parecia algo estável e simples, com o progresso das técnicas de impressão, o sucesso da imprensa escrita e a generalização da obrigatoriedade escolar para as crianças, tornando o papel da comunicação escrita cada vez mais importante. Com o advento do gramofone, do rádio, da fotografia, do cinema, da televisão e do computador, ganham novamente força as imagens e a palavra falada (Claval, 2003). Ao mesmo tempo, a existência de redes de comunicação planetária e a simultaneidade das trocas fazem desaparecer as antigas estruturas e hierarquias que, no passado, pareciam naturais.

No entanto, essa revolução é diversamente experienciada nos diferentes lugares do mundo contemporâneo, ensejando uma análise geográfica da disseminação das técnicas de comunicação e informação a partir dos processos de apropriação socioespacial dos objetos técnicos em sua dimensão local/regional/nacional.

Uma análise multiescalar das táticas de apropriação das técnicas de informação e comunicação pensando os lugares como plataformas para a elaboração de ações e discursos de diferentes grupos e iniciativas da cena alternativa e popular em Salvador e Berlim é apresentada no livro Lugar e Mídia, publicado pela Editora Contexto em 2011. Pretende-se retomar aqui algumas das discussões apresentadas no livro, intentando-se sua atualização e buscando-se refletir sobre as noções de justiça espacial e acessibilidade às tecnologias de informação e comunicação em diferentes escalas e recortes espaciais no contexto nacional, regional e local. 
Lugar e mídia - Enunciação de lugares a partir de fatos históricos em bairros populares de Salvador

No livro Lugar e Mídia, buscou-se compreender como os lugares são enunciados no cotidiano das duas cidades analisadas, destacando-se o papel da comunicação para a elaboração de representações espaciais multiescalares, que abrem grupos e iniciativas para o mundo. Para esses grupos e iniciativas trata-se de viabilizar um espaço de mediações, uma esfera pública urbana renovada, regida por uma nova ética capaz de nortear a um só tempo ação e discurso e produzir/ enunciar um "lugar".

Essa (nova) ética se baseia em princípios de cunho tático e, muitas vezes, subverte, pelo uso e pela ação, as estratégias de grupos hegemônicos, como sublinhado por Michel de Certeau (1994), nos processos de produção do espaço. Na ausência de um lugar, de "um próprio", esses grupos e iniciativas enunciam o "lugar" através de ações calculadas - táticas.

A relação entre lugar e mídia pressupõe articulação e encontro em processos capitaneados por grupos e iniciativas atuantes na cidade contemporânea, em momentos e espaços específicos. Espaços-tempo de representação e comunicação que vão mediar processos de apropriação socioespacial da técnica e sua "tradução" em tecnologia.

Parte-se do pressuposto de que as técnicas influenciam o modo como percebemos o espaço e o tempo, não só por sua existência física, mas também pela maneira como afetam nossas sensações e nosso imaginário. Por outro lado, como já mencionado na introdução, os lugares vão se relacionar de modo diferenciado com as técnicas e os objetos técnicos, de acordo com as condições que oferecem enquanto "meio operacional", para viabilizar a produção, a circulação, a comunicação, o lazer etc. (Santos, 1996).

São relações de proximidade imediata, baseadas em ações solidárias, "comunitárias", "populares" e/ou "alternativas", a depender do contexto. Essas relações são condicionadas por táticas diferenciadas de comunicação e representação e, ao mesmo tempo, condicionam a atuação de grupos e iniciativas nos diferentes lugares urbanos, revelando esses últimos como bases para a instalação/ a consolidação de um "meio operacional" para a ação e o discurso.

As análises apresentadas no livro supracitado (Serpa, 2011) evidenciam também que as relações entre lugar e mídia vão ser de algum modo determinadas pela densidade deste meio operacional em cada 
lugar concreto, bem como pela acessibilidade a este meio para grupos e iniciativas que se apropriem taticamente destes "recursos". Com níveis bastante diferenciados em termos de densidade e acessibilidade, Salvador e Berlim mostram-se, ambas, como aglomerações metropolitanas capazes de oferecer brechas espaciais ou "lugares do possível", nos termos de Lefebvre (1991), para o uso criativo da técnica e sua transmutação em tecnologia "apropriada”, ressignificada pelo uso "popular" e/ou "alternativo".

Pode-se afirmar que, ao se apropriar dos meios de comunicação, enunciando "lugares" nos termos colocados por Michel de Certeau (1994), esses grupos e iniciativas exercitam a um só tempo as artes do fazer e do falar, ressignificando os lugares onde atuam e efetivando, no cotidiano destas áreas, táticas de uso e apropriação, que se revelam através de práticas socioespaciais específicas. Percebe-se que os lugares são enunciados a partir de elementos histórico-sociais presentes nas áreas de atuação, a partir de uma "efetuação criativa do sistema linguístico", recontando, inclusive, sob outros olhares, a história das cidades.

Grupos que produzem conteúdos para sites de utilidade pública nos bairros de Salvador vão se apropriar, de acordo com táticas e interesses determinados, da história dos lugares de atuação, produzindo conteúdos para a Internet os quais, de certo modo, revelam certa congruência com o histórico de desenvolvimento urbano da cidade. O contraste entre Cidade Baixa e Cidade Alta, por exemplo, remete aos primórdios da ocupação urbana na capital baiana.

Se, no século XVI, Salvador era ainda um conjunto de casas baixas e modestas, "embora ostentasse o título de cidade" já nessa época, no século XVIII se transformou efetivamente em uma "cidade imponente, senhorial", como descrito por Antônio Risério, em Uma história da cidade da Bahia (2004). Vista de longe, a partir das embarcações que aportavam na cidade mercantil, o conjunto urbano disposto em dois planos causava êxtase aos visitantes estrangeiros, mas era substituído "pelo choque decepcionante", tão logo desembarcavam na Cidade Baixa, onde se chocavam com a "imundície da rua da Praia", quadro que "enojava" e "horrorizava" os recém-chegados, conforme descreve Risério (2004, p. 295-296).

É evidente, na leitura da obra de Risério, um contraste acentuado e extremo entre as cidades alta e baixa na Salvador oitocentista. Esse contraste é evidenciado através de uma nítida estratificação das duas cidades, a Cidade Baixa como lugar do pequeno e do grande comércio, a cidade malsã e mal cheirosa, cidade negra e cidade escrava, armazém, 
porto e empório, e a Cidade Alta como lugar silencioso e bem ornado, luminoso e amplo, cidade cartão-postal, branca e senhorial (Augel apud Risério, 2004).

Esse contraste, travestido nos séculos seguintes em uma espécie de "estigma espacial”, é um dos argumentos para a criação do site CidadeBaixa.com, que tem como slogan "a Cidade Baixa conectada com o mundo". O site pretendia, à época de nossas pesquisas, também tornar a Cidade Baixa mais conhecida para o restante da cidade, enaltecendo sua história e seus pontos turísticos. Não à toa contava com o apoio da Bahiatursa, órgão estadual de fomento ao turismo. No link "História”, o site enunciava o lugar a partir de elementos encontrados em fontes históricas oficiais.

Observou-se, no entanto, que não havia menção à estratificação de Salvador em duas cidades, nos termos anteriormente colocados por Risério, denotando claramente a intenção de contornar o estigma espacial, omitindo da história contada no site algo que pudesse comprometer as táticas de enunciação de um lugar com grande potencial turístico, supostamente desconhecido do restante da cidade. Em pesquisas anteriores do Grupo Espaço Livre de Pesquisa-Ação, que coordeno na UFBA, realizadas no bairro da Ribeira, localizado na península de Itapagipe, na Cidade Baixa, constatou-se que alguns moradores mais antigos estendiam seus limites até o Largo de Roma, praticamente incluindo a península de Itapagipe inteira no bairro da Ribeira. Entre os que participavam de associações de bairro, havia uma tendência a não reconhecer de imediato os limites da Ribeira, afirmando o distrito de Itapagipe como “bairro”. Há aqui uma estratégia de valorização turística englobando os monumentos e atrativos de bairros vizinhos como o Bonfim e Monte Serrat (Serpa, 2007).

É verdade que em outros bairros da cidade, onde analisamos as táticas de apropriação socioespacial dos meios de comunicação por grupos populares, nem sempre era clara a distinção entre bairro e região administrativa. Em Salvador, bairros mais antigos como a Liberdade e a Boca do Rio se diferenciaram com o tempo, originando novos bairros como o Curuzu (no primeiro caso), o Stiep e o Costa Azul (no segundo). Hoje, são nomes de regiões administrativas (que coincidem com o bairro original), mas os limites da região não coincidem mais com os limites do bairro atual.

Por outro lado, isso não se constitui uma regra para todos os bairros analisados. Em Pirajá, bairro popular centenário da capital baiana, não 
era a região administrativa como conjunto de bairros que embasava a ação e o discurso dos produtores de conteúdos para o Portal Pirajá (portalpiraja.org). Ali era a história do bairro que contava, por este ter sido palco das lutas pela independência da Bahia, algo sublinhado tanto nos textos disponibilizados no site como na entrevista com seu organizador. Ou seja, os espaços de representação oscilavam, à época de nossas pesquisas, entre bairro e distrito, nos sites de utilidade pública analisados, ora enfatizando-se um, ora colocando-se a ênfase em outro, o que diz muito sobre o caráter processual dos lugares urbanos, enunciados e representados a partir de táticas diferenciadas de comunicação.

Tecnologia e Lugar - o contexto ao final da primeira década do século XXI no Brasil e na Alemanha

Acesso universal à Internet com baixo custo parece um sonho ainda distante no Brasil, onde a proporção de domicílios com computador não superava a marca dos 36\% em 2009 (TIC Domicílios²). Na região Nordeste esse percentual era ainda mais baixo, não ultrapassando $18 \%$ (em comparação com a região Sudeste, com 45\%, e a região Sul, com 43\%, dados de 2009). Se considerássemos somente aqueles computadores com acesso à Internet esses números caíam, respectivamente, para módicos 27\% (Brasil) e 13\% (Nordeste) (dados de 2009).

O local de acesso à Internet evidenciava no final da primeira década dos anos 2000 que as lan-houses superavam os domicílios nas menores faixas de renda: $72 \%$ até um SM; $60 \%$ entre 1 e 2 SM; $44 \%$ entre 2 e 3 SM contra $38 \%$ entre 3 e 5 SM; $27 \%$ entre 5 e 10 SM e 16\% com 10 SM ou mais (TIC Domicílios, dados de 2009). Independentemente da faixa de renda, $30 \%$ dos brasileiros acessavam a Internet em casa e 54\% em lan-houses.

$\mathrm{Na}$ Bahia, o acesso à Internet deu um salto relativo, entre os anos de 2003 e 2009, de acordo com Pesquisa Nacional por Amostra de Domicílios (PNAD), divulgada em setembro de 2009 pelo IBGE: 17,1\% dos domicílios do Estado possuíam computadores com conexão, em 2003 essa taxa era quatro vezes menor, de apenas 4,67\%. Em Salvador, 33,4\% dos imóveis possuíam, em 2009, acesso à rede mundial, em 2003 o percentual era de 11,7\%.

Na Alemanha, o acesso às tecnologias de informação e comunicação é mais universalizado e a discussão se dá em outras bases. Como em Berlim, onde 73,3\% dos domicílios dispunham em 2009 de computador 
com acesso à Internet e a administração municipal desejava à época abrir licitação para implantação de uma rede sem fio que cobrisse todos os espaços públicos da cidade.

Vivia-se em Berlim - na época de realização de nossas pesquisas na cidade - a era da universalização da rede WLAN (sem fio), algo ainda inimaginável no contexto brasileiro atual. A ideia era instalar roteadores e antenas em semáforos, postes de iluminação e telhados de edifícios públicos, o que vinha causando polêmica, considerando-se o impacto visual e a possibilidade de problemas de trânsito, em decorrência de possíveis falhas de sincronização com os semáforos. Mas essa não era a única causa de insatisfação em Berlim. Muitos gostariam que a infraestrutura fosse de fato pública e não explorada pela iniciativa privada.

Em Berlim, uma rede sem fio nas mãos dos usuários já era realidade na cidade desde 2002: a iniciativa Freifunk ("Onda Livre”), que reunia muitos adeptos, principalmente no lado oriental da cidade, em distritos como Friedrichshain, Mitte e Prenzlauer Berg. Nesses distritos, logo após a queda do muro, a empresa de comunicação alemã Telekom instalou cabos de fibra ótica, na época a tecnologia mais moderna para acesso à Internet rápida. Com o advento da Internet sem fio, esses cabos se mostraram inapropriados, já que a instalação de uma infraestrutura de WLAN requeria cabos de cobre: isso deu origem à rede Freifunk, fruto da organização dos habitantes, que ao longo dos anos conseguiram instalar uma (impressionante) estrutura descentralizada de WLAN, a um custo muito baixo e sem necessidade de conexão com um provedor central.

A rede Freifunk desconstrói a ideia de que a tecnologia separa e isola as pessoas nas metrópoles contemporâneas, porque exige de seus usuários estratégias de organização baseadas no encontro e na co-presença entre vizinhos, fortalecendo as redes sociais nos distritos onde se insere.

Para se conectar à rede Freifunk, o novo usuário precisava apenas de um roteador reconfigurado, um computador e alguém nas vizinhanças que já participasse da rede. Os usuários compartilhavam programas gratuitos disponibilizados na plataforma Freifunk, além de uma infraestrutura de vizinhança, como antenas nos telhados dos prédios. Para iniciantes havia em 2009 um encontro semanal, no centro da cidade, quando experiências e dúvidas eram compartilhadas com os mais "veteranos" na rede.

A rede Freifunk não se restringia apenas ao acesso à Internet. $\mathrm{O}$ intercâmbio de arquivos era mais intenso entre os participantes do que 
na WLAN comercial. E isso não ocorria por acaso, como nos explicou Jürgen Neumann ${ }^{3}$, um dos muitos porta-vozes da rede:

É muito mais rápido baixar um vídeo no computador a partir de um site, do que enviar um vídeo produzido por você para o youtube, porque, desde o início, os provedores da infraestrutura queriam transformar os usuários em consumidores que não produzem conteúdos para a rede.

Ou seja: a tecnologia ADSL (Asymmetric Digital Subscriber Line), que baseia a WLAN comercial determina velocidades maiores para baixar arquivos e menores velocidades para enviá-los. Além disso, na rede Freifunk, todos dispunham de um endereço fixo de IP (ao contrário da Internet sem fio convencional), o que facilitava a conexão direta e o compartilhamento de conteúdos entre os participantes.

Se no contexto alemão Freifunk significa uma rede autônoma e não hierárquica de comunicação, no Brasil poderia representar uma possibilidade real de acesso à rede mundial de computadores de modo criativo, participativo e compartilhado para aqueles que de fato necessitam dessa técnica e não podem assumir os (ainda altos) custos para sua instalação.

Deve-se mencionar aqui o projeto Infovia Municipal de Salvador SSA Digital, que objetivava dar completa cobertura de Internet sem fio na cidade até a Copa de 2014. Pretendia-se instalar Internet sem fio gratuita em 40 espaços públicos da capital baiana até o final de 2010, mas somente 4 pontos foram de fato implantados (Praça Municipal, Praça João Martins, em Paripe, Praça do Imbuí e Praça Regina Guimarães, na Fazenda Grande), com um custo de 200 mil reais aos cofres públicos (Vasconcelos; Anjos, 2010, p. A4).

No entanto, em 2010, o serviço era praticamente desconhecido para a maioria dos potenciais usuários. Os poucos que tinham conhecimento do projeto se questionavam sobre quem teria coragem de abrir um notebook para ficar à mercê de ladrões em um espaço público. Além disso, o serviço não exigia identificação dos usuários, o que, de acordo com especialistas, poderia favorecer os chamados crimes "virtuais" (Vasconcelos; Anjos, Jornal A Tarde, 08/07/2010, p. A4).

A comparação entre contextos socioespaciais tão díspares, embora passível de questionamentos, retoma a questão colocada na introdução, de que a investigação sobre as relações entre mídia e lugar, entre tecnologia 
e lugar, requer uma avaliação do espaço como meio operacional e como meio percebido/ concebido, de acordo com as ideias de Milton Santos (1996). É dos resultados de uma investigação assim que se pode inferir o papel e a importância dos lugares para a apropriação da técnica e sua transformação, através do uso e da apropriação, em tecnologia. Para a Geografia, trata-se de enfatizar a dimensão espacial destes processos, a partir da atuação de grupos e iniciativas que enunciam "lugares" e produzem espaço em contextos espaço-temporais específicos.

Esse "novo meio técnico" (composto por comunicação e informática, por linguagens e equipamentos) desempenha um papel que vai além da função de sustentáculo da ação humana, já que é, ele próprio, segundo Ana Clara Torres Ribeiro, "intrinsecamente ação":

Por esse motivo, a sua natureza é estratégica e, virtualmente, instituinte. Esse meio emite, junto com a informação, exigências e ordens. Em consequência, o desvendamento de outros usos sociais da (e para a) técnica constitui-se num dos maiores desafios enfrentados pelos que procuram por projetos para a defesa de um futuro melhor (Ribeiro, 2008, p. 191, grifo do autor).

Ribeiro enfatiza a necessidade de reconhecimento das forças políticas e sociais que vão se apropriar do espaço herdado e das potencialidades da técnica. Concordamos também com sua afirmação de que não há neutralidade na tecnologia e que a "liberdade não emana diretamente da técnica” (Ribeiro, 2008, p. 195), acrescentando que é nos lugares de atuação de grupos e iniciativas que se apropriam dos meios de comunicação, que a técnica pode possibilitar o surgimento de usos criativos de uma tecnologia autônoma e, por que não dizer, "livre" em suas acepções e significados.

Os sites de utilidade pública nos bairros populares de Salvador - menor acesso à técnica e mais conteúdo "local" para a Internet

Em Salvador, o acesso à técnica pelos produtores/ organizadores dos sites de utilidade pública com atuação nos bairros populares da cidade era muito mais restrito que em Berlim no ano de 2009. Muitas vezes, o discurso e a ação destas iniciativas eram claramente norteados pelos limites relativos à infraestrutura disponível, como nos explicou Fábio Ferreira, do Portal Pirajá, já que nem todos possuíam em casa um 
computador com acesso à Internet: "Aqui no bairro, temos uma sala, tipo uma lan-house, onde é atualizado o site. Rogério também faz a atualização na casa dele. Ele e eu nos comunicamos muito pelo MSN: eu passo a notícia para ele atualizar. É sempre uma troca de informações”."

Portanto, mesmo quem atualizava o site podia não ter um computador com acesso à Internet em casa, como mostra o exemplo do site Portal Pirajá. Ferreira demonstrava, no entanto, alguma familiaridade com a técnica, repassando de diversas maneiras matérias jornalísticas para o colega Rogério: "Envio as matérias pro e-mail dele. No site tem uma página de arquivo, a qual só nós temos acesso, enviamos as notícias assim também. A partir daí, Rogério acessa essa página e coloca no site”. Ferreira se preocupava também com o controle do número de acessos e explicou o uso da ferramenta que lhe permitia inferir o alcance de sua iniciativa:

Temos uma página que nos possibilita saber todos os acessos que o site teve, além dos horários. Temos um controle diário, uma média de 17 pessoas por dia. Isso se intensificou depois da divulgação (do site). Desde que foi lançado, o site teve uma média de 1.500 acessos.

A preocupação com o número de acessos permeava também o discurso de Elton Serra, do site CidadeBaixa.com, que, do mesmo modo que Fábio Ferreira, demonstrava familiaridade com as ferramentas operacionais do sistema: "Temos uma média mensal de sete a oito mil acessos. Temos essa informação através da parte operacional do site, a qual permite que saibamos até de onde a pessoa está acessando. O próprio sistema informa”. Ao contrário do site Portal Pirajá, Serra e outro colega possuíam computador em casa, atualizando os conteúdos do CidadeBaixa. com a partir de suas residências, localizadas nos bairros da região.

Percebeu-se entre os grupos que administravam os sites em Salvador uma maior preocupação com a produção de conteúdos para a Internet, em geral baseados na coleta de informações no cotidiano dos bairros e localidades onde atuavam estas iniciativas. Preocupavam-se, também, com a caracterização do perfil do público para qual eram direcionadas estas informações e conteúdos:

A própria comunidade que frequenta lan-house ou que tem computador em casa acessa muito nosso site. Hoje estamos conseguindo abranger um grande número de usuários, principalmente pessoas do bairro que labutam com informática. Pessoas ligadas às associações de bairros também fazem parte desse perfil. Hoje eu faço parte 
da união dessas associações, então permitimos que elas possam divulgar seus eventos através do site (Fábio Ferreira, Portal Pirajá).

As táticas de produção dos conteúdos se baseavam, sobretudo, no ativismo de bairro e na atuação dos coordenadores dos sites em suas localidades, mostrando também uma superposição de papéis no cotidiano dos grupos e iniciativas analisados em nossas pesquisas. Além disso, os próprios sites forneciam mecanismos para levantamento de conteúdos de interesse para as localidades ("Fale Conosco"), posteriormente debatidos e aprofundados em reuniões periódicas dos grupos:

Eu busco os conteúdos através dos trabalhos que realizo com as associações. Fazemos levantamentos a partir da participação no Fale Conosco. Temos reuniões aqui todas as terças-feiras, pois sou líder da 'Terceiro Milênio', que é a união de todas as associações. Eventos, problemas do bairro com relação a transporte são discutidos nas reuniões das associações e viram notícias, pois são importantes para a comunidade (Fábio Ferreira, Portal Pirajá).

Cajazeiras é uma cidade em movimento, até em você sair na rua, já é fácil encontrar matéria. Aqui na Rótula da Feirinha, que é o coração do bairro, ficamos sabendo de muitas coisas. Temos também o Fale Conosco, uma seção na qual as pessoas contribuem com informações, que acabam virando matérias. Temos reuniões, nas quais nós decidimos o que vai ou não entrar no ar. Acho importante analisar as notícias antes de divulgá-las, para colocar no ar assuntos que realmente interessem ao bairro (Roberto Oliveira, Cajazeiras.net).

Observou-se que, entre as iniciativas analisadas em Salvador, havia uma maior preocupação com a produção de conteúdos locais para os sites de utilidade pública, embora fossem evidentes também maiores dificuldades de acesso às novas tecnologias informacionais do que em Berlim. Na capital alemã, por outro lado, o exemplo da rede Freifunk demonstrava maior domínio e autonomia dos participantes para a construção de uma infraestrutura mais universalizada de acesso à Internet, com ênfase na descentralização e na autogestão.

Isso não quer dizer, no entanto, que em Berlim não houvesse na época de nossas pesquisas produção de conteúdos para a rede mundial de computadores entre os grupos e iniciativas analisados. Ao contrário, havia uma relação muito mais estreita entre os diferentes meios de comunicação, proporcionando maior disponibilização de conteúdos e uma mais ampla 
interface entre as diferentes linguagens - texto e audiovisual - através das ferramentas digitais da Web 2.0 ${ }^{6}$, como analisamos em detalhes no livro Lugar e Mídia (Serpa, 2011).

Lugar e mídia, justiça espacial e novas perspectivas

Praticamente uma década depois da realização das pesquisas em Salvador e Berlim e seis anos desde a publicação do livro Lugar e Mídia (Serpa, 2011), novas perspectivas se abrem para a análise aqui proposta.

Um caminho profícuo é justamente a noção de justiça espacial, a partir da análise do espaço não como um mero receptáculo das novas técnicas e tecnologias, mas como instância central e fundamental para revelar as desigualdades de acesso às novas tecnologias de informação e comunicação, especialmente no tocante à acessibilidade a esse novo meio técnico-científico-informacional, sob relações capitalistas de produção, agora como nunca norteadas pela inteligência e pela informação.

Que cidade digital é essa que se esboça, especialmente no Brasil, em um quadro gritante de injustiça espacial? Nesse contexto de desigualdades socioespaciais ainda mais agravadas em todas as escalas como pode ser observado nesta segunda década dos anos 2000?

Uma simples e breve consulta aos resultados da última pesquisa TIC Domicílios de 2015 pode nos ajudar nessa empreitada. A difusão das Tecnologias de Informação e Comunicação nas últimas décadas em países subdesenvolvidos - inclusive e com muita força no Brasil - é hoje um fato inquestionável, que perpassa inclusive classes sociais distintas. A última pesquisa TIC domicílios realizada em 2015 no Brasil mostra, por exemplo, algumas tendências:

- O avanço do número de usuários de Internet entre os brasileiros com 10 anos ou mais, bem como sua frequência de uso. A tendência é de aumento progressivo na proporção de usuários que acessam a Internet todos os dias ou quase todos os dias, passando de 53\%, em 2008, para 82\%, em 2015.

- Um dos destaques da edição de 2015 da pesquisa TIC Domicílios diz respeito aos dispositivos utilizados para o acesso à Internet. Enquanto em 2014 os computadores (de mesa, notebook ou tablet) eram os dispositivos mais utilizados para acessar a rede (80\%), em 2015 o telefone celular passou a ser o principal equipamento usado para essa atividade (89\%, percentual que era de $76 \%$ em 2014). 
- O acesso à Internet exclusivamente por meio do celular também foi mais frequente entre os usuários que residem nas regiões Nordeste (43\%), Norte (55\%) e nas áreas rurais (56\%), o que reforça a hipótese de que o telefone celular se configura como alternativa para o uso da rede nas áreas em que a infraestrutura de Internet fixa é mais precária.

- Em 2015, 35\% dos usuários de Internet acessaram a rede apenas pelo telefone celular, sendo que em 2014 essa proporção era de 19\%. O uso exclusivo pelo telefone celular ocorre especialmente entre os usuários de classes sociais menos favorecidas.

Obviamente o acesso à Internet ainda é ainda muito desigual no Brasil, e as desigualdades se manifestam tanto em termos de perfil socioeconômico da população como em termos regionais/espaciais. Nesse ponto, convém enfatizar, a partir das afirmações de Ana Fani Carlos (2011, p. 66-67) que:

o espaço geográfico revela-se em suas dimensões material - que se refere à dimensão física, espaço tempo da vida real [...] concreta - [...] a sociedade produzindo e reproduzindo-se e tomando consciência de sua produção [...] (e) abstrata - [...] o plano conceitual, no qual o conhecimento e a análise descobrem categorias novas.

A ênfase nas dimensões material e concreta sublinha a importância do cotidiano para a compreensão do espaço produzido e reproduzido na contemporaneidade, enquanto no plano abstrato, igualmente importante, representações sociais e espaciais são produzidas em relação dialética com a concretude e a materialidade de lugares, regióes, territórios e paisagens, mediando as relações sociedade-espaço.

O próprio Comitê Gestor da Internet no Brasil, no livro eletrônico que divulga os dados da TIC domicílios 2015 (CGI.br, 2016), corrobora, logo na introdução da referida publicação, nossas preocupações e a atualidade da discussão aqui proposta:

Ao chegar ao seu $11^{\circ}$ ano de produção de dados sobre o acesso das tecnologias de informação e comunicação (TIC) nos domicílios e o seu uso pelos brasileiros, a pesquisa TIC Domicílios 2015 mostra que a incorporação das tecnologias digitais móveis para o acesso à Internet é cada vez maior e mais frequente no cotidiano dos brasileiros. Por um lado, esse avanço é importante e merece ser comemorado. Contudo, as enormes disparidades entre regiões do país e classes sociais em relação ao acesso e uso das TIC permanecem nesse novo cenário. Os maiores desafios para as políticas 
públicas de inclusão digital no país são a universalização do acesso em banda larga nos domicílios das classes economicamente menos favorecidas e o fomento ao desenvolvimento de habilidades digitais que possibilitem um uso proficiente de funções e aplicações mais complexas, requerido pelas empresas que já operam sob uma nova lógica da economia digital. Merece atenção o estudo das barreiras que impedem que mais brasileiros usufruam das oportunidades trazidas pelas novas tecnologias digitais, indo além de um uso puramente instrumental das TIC (CGI.br, 2016, p. 25).

Um olhar sobre as grandes regiões do país e os dados divulgados na TIC 2015 confirma que problemas de disponibilidade de rede e velocidade de conexão ainda permanecem na escala regional, evidenciados quando realizadas comparações regionais, com os estados das regiões Norte e Nordeste situando-se em posição de desvantagem. Nesse contexto, as regiões Centro-Oeste, Sul e Sudeste apresentaram, respectivamente, $40 \%, 28 \%$ e $22 \%$ de domicílios com conexão de velocidade superior a 8 Mbps, enquanto as regiões Norte e Nordeste apresentavam 17\% e 15\%, respectivamente, de domicílios nesta condição, no ano de 2014 (CGI. br, 2015 apud CGI.br, 2016, p. 56-57): "Entretanto, mesmo nas regiões melhor atendidas pela infraestrutura e serviços de Internet, encontra-se desigualdade, tanto intrarregional como no interior de uma mesma área urbana" (CGI.br, 2016, p. 56-57).

Embora se observe, ao longo da série histórica da pesquisa TIC Domicílios, uma perspectiva de aumento do número de residências com computador, esse quantitativo chegando, em 2015, a 33,2 milhões de domicílios com acesso ao equipamento e, mesmo que a proporção de domicílios com computador tenha dobrado desde 2008, saltando de $25 \%$ naquele ano para $50 \%$ em 2015 , a pesquisa aponta para certa estabilidade a partir de 2013:

A penetração de computadores nos domicílios ainda é desigualmente distribuída, especialmente no que diz respeito às distâncias relativas observadas entre regiões e diferentes classes sociais. As maiores proporções de presença de computadores nos domicílios seguem sendo verificadas no Sudeste (59\%) e no Sul (54\%). Enquanto nas regiões Centro-Oeste, Nordeste e Norte essas proporções são de $44 \%$, $38 \%$ e $30 \%$, respectivamente. 
O mesmo padrão de persistência das desigualdades se manifesta entre as áreas urbanas e rurais do país. Embora, desde 2008, tenha havido um crescimento significativo da proporção de domicílios rurais com acesso ao computador, a diferença em relação às áreas urbanas ainda perdura. Em 2015, 54\% dos domicílios da área urbana possuíam pelo menos algum tipo de computador, mais que o dobro do percentual relativo à área rural (25\%).

Por fim, com relação às desigualdades socioeconômicas é possível notar [...] que os percentuais de acesso a esse equipamento nas classes C e DE eram significativamente inferiores aos das classes A e B: observa-se a universalização da presença desse tipo de dispositivo na classe A, enquanto nas classes DE, pouco mais de 1 em cada 10 domicílios possuía computador.

Também é importante destacar que, na região Sudeste - que tinha a maior proporção de domicílios com computadores no país -, havia um total de 11,9 milhões de domicílios sem esses dispositivos. No Nordeste esse contingente era de 10,8 milhões de domicílios. Se, por um lado, os dados reforçam a importância de políticas públicas que minimizem as desigualdades estruturais do país, por outro, é necessário atentar para o fato de que ações localizadas em segmentos ou regiões específicos não serão necessariamente efetivas. Arranjos e políticas complementares deverão ser adotados para que sejam superadas as dinâmicas das desigualdades (CGI.br, 2016, p. 128).

Levando-se em conta o acesso domiciliar à Internet também ficam evidenciadas as desigualdades regionais, que persistem na atualidade: entre as regiões do país, o Norte possuía menor percentual de domicílios com acesso à Internet (38\%), ao contrário do Sudeste, onde havia o maior percentual de domicílios conectados entre as regiões brasileiras (60\%). O Nordeste tinha, em 2015, 40\% de domicílios com acesso à rede mundial de computadores, enquanto o Sul apresentava um percentual de $53 \%$ e o Centro-Oeste de 48\% (CGI.br, 2016, p. 133). Na escala nacional, em 2015, $41 \%$ do total de domicílios tinham acesso à Internet e a computador, outros $9 \%$ possuíam conexão à rede sem computadores. Outra parcela de $8 \%$ de domicílios contava com computador, mas estavam desconectados e outros $41 \%$ não tinham nem computador e nem acesso à Internet (27,3 milhões de domicílios) (CGI.br, 2016, p. 132). 
Em relação à primeira década dos anos 2000, a perspectiva é de declínio do uso das lan-houses ${ }^{7}$ e de mudança de público usuário para acesso à rede mundial de computadores na década atual:

Os centros públicos de acesso gratuito, como telecentros, bibliotecas e entidades comunitárias (14\%), e de acesso pago, como lan-houses e cybercafés (12\%), continuam sendo menos mencionados como locais de uso entre os usuários de Internet. Contudo, observa-se o aumento do uso em centros de acesso gratuito de 2014 (8\%) para 2015 (14\%). Esse movimento não significa necessariamente um aumento do uso da rede em telecentros. Além das políticas públicas das diversas esferas de governo de oferta de acesso à Internet gratuito em locais públicos, como praças e outros equipamentos, é possível que esse aumento se deva também a uma maior disponibilidade de pontos de conexão gratuitos via WiFi providos por outros tipos de locais, como estabelecimentos comerciais, em resposta à demanda crescente de uso da Internet via telefones celulares (CGI.br, 2016, p. 147).

De acordo com Junqueira (2012, on-line), desde 2010, o acesso doméstico superou as lan-houses. Naquele ano, 28\% dos brasileiros tinham nesses estabelecimentos uma das maneiras de acessar a Internet, frente aos outros 67\% que o faziam a partir de casa (TIC Domicílios e Usuários de 2011). E isso fez mudar o perfil do público-alvo das lan-houses de modo decisivo no Brasil: "Se antes os centros eram populares entre jovens de classe média, atualmente são um meio de promover a inclusão digital no Brasil” (Junqueira, 2012, on-line).

Justiça espacial: direitos sociais, localização e cidadania

Tendo em vista os dados aqui apresentados pode-se concluir que persistem as desigualdades regionais e locais em território nacional. Também é possível afirmar que o acessos às Tecnologias de Informação e Comunicação se modificaram sobremaneira no Brasil de 2009 a 2015, com um relativo aumento de acessibilidade, propiciado pelos aparelhos celulares. Várias evidências apontam para essas mudanças, como a diminuição considerável do número de lan-houses, principal forma de acesso das classes populares à rede mundial de computadores na primeira década dos anos 2000.

Hoje, as desigualdades se expressam muito mais nas velocidades de acesso à Internet, que se pode adquirir no mercado com recursos 
próprios, o que evidencia desigualdades sociais e espaciais marcantes no tocante às TICs. Persistem também as dificuldades de acesso na escala intraurbana, fato ainda bastante presente nos bairros populares das metrópoles brasileiras. Dos três sites de bairros analisados em 2009 em nossas pesquisas em Salvador, por exemplo, apenas um permanece online e ativo, o CidadeBaixa.com, enquanto o projeto Infovia Municipal de Salvador - SSA Digital não avançou para alcançar outros espaços públicos da cidade, o que demonstra que "no cotidiano social existem cidadãos que [...] vivem em lugares - porções discretas - dos territórios nacionais" (Castro, 2005, p. 202) e que a relação entre localização e cidadania deve ser sempre levada em conta nas análises de justiça espacial. O indivíduo é mais ou menos cidadão a depender do lugar onde está, como diria Milton Santos (1993).

A análise das tendências e perspectivas recentes relativas à disseminação e ao acesso das/ às Tecnologias de Informação e Comunicação no território nacional abre caminho também para uma melhor compreensão da noção de justiça espacial e o papel do espaço como instância fundamental para o exercício da cidadania e dos direitos civis, políticos e sociais, pois, como nos lembra Iná Elias de Castro,

Sendo uma questão de fundo moral da organização da vida social, afetada pela história e recortada pelo espaço, a cidadania como prática constitui, por si, um balizamento e uma perspectiva possíveis para abordar a relação entre o território e a sociedade. A ideia de prática remete necessariamente ao conjunto de instituições que organizam, numa dada base territorial, as possibilidades de exercício dos direitos e deveres dos cidadãos vis-à-vis à comunidade e vice-versa (Castro, 2005, p. 202).

Se analisarmos o acesso a esse meio operacional e sua apropriação como meio percebido/concebido como um direito social e, considerando, com Castro, que "o exercício de direitos sociais requer uma base infraestrutural [...] apoiada nas instituições públicas", e que, "num país como o Brasil a localização pode constituir um facilitador ou uma dificuldade ao exercício desses direitos” (Castro, 2005, p. 204), então é a "inserção territorial das instituições, corporificadas nas organizações, o que confere as condições de acesso aos direitos sociais" (Castro, 2005, p. 203). À Geografia caberia analisar de que maneira este meio operacional se concretiza e organiza espacialmente, em um contexto de grandes desigualdades socioespaciais como no Brasil, apostando numa análise 
multiescalar do problema e no aprofundamento analítico das dimensões de classe envolvidas nesses processos, especialmente naqueles que embasam as táticas de apropriação criativa da técnica e sua elaboração/ transformação em tecnologia.

\section{Notas}

1 Conferência de abertura da Reunião da Comissão de Geografia Urbana da União Geográfica Internacional - UGI, proferida em inglês, no dia 7 de agosto de 2017, em SalvadorBahia (https://www.unil.ch/igu-urban/home/menuinst/urban-commission-meetings/2017salvador-de-bahia.html).

2 CETIC. BR. 2009. Disponível em:<http://www.cetic.br/usuarios/tic/2009/ticdomicilios-2009.pdf>. Acesso em: 25 maio 2017.

3 Entrevistado pelo autor em Berlim, em 25 de agosto de 2009.

4 Entrevistado pelo Grupo Espaço Livre (UFBA) em Salvador, em setembro de 2007.

5 Entrevistado pelo Grupo Espaço Livre (UFBA) em Salvador, em setembro de 2007.

6 Web 2.0 é um termo criado em 2004 pela empresa estadunidense O'Reilly Media para designar uma segunda geração de comunidades e serviços, tendo como conceito a 'Web como plataforma', envolvendo wikis, aplicativos baseados em folksonomia, redes sociais e Tecnologia da Informação. Embora o termo tenha uma conotação de uma nova versão para a Web, ele não se refere à atualização nas suas especificações técnicas, mas a uma mudança na forma como ela é encarada por usuários e desenvolvedores, ou seja, o ambiente de interação que hoje engloba inúmeras linguagens e motivações (Fonte: WIKIPEDIA. A enciclopédia livre. Web 2.0. (on-line). Disponível em:< https://pt.wikipedia. org/wiki/Web_2.0>. Acesso em: 22 set. 2017.).

7 É difícil medir a quantidade exata de lan-houses disponíveis no Brasil. Números do governo federal estimam que existam entre 18 e 20 mil casas registradas. No entanto, há quem especule que até $90 \%$ delas estejam na informalidade. O TIC Lan-Houses 2010 aponta que há dois anos existiam mais de 100 mil estabelecimentos espalhados pelo Brasil, entre os formais e os informais, com maior concentração especialmente no Norte, Nordeste e em bolsões de baixa renda. Esses estabelecimentos são pequenos e com perfil familiar. Em 2010, 97\% das lan-houses tinham até três funcionários e $70 \%$ até dez computadores (Junqueira, 2012). Disponível em: <https://olhardigital.uol.com.br/ noticia/lan-houses-as-casas-de-jogos-se-tornaram-centros-de-inclusao-digital/28528>. Acesso em: 28 maio 2017.

\section{Referências}

AUGEL, Moema Parente. Visitantes estrangeiros na Bahia oitocentista. São Paulo: Cultrix; Brasília: INL, 1980.

CARLOS, A. F. A. A condição espacial. São Paulo: Contexto, 2011. 
CASTRO, I. E. de C. Geografia e política. Territórios, escalas de ação e instituições. Rio de Janeiro: Bertrand Brasil, 2005.

CERTEAU, M. de. A invenção do cotidiano. 2. ed. Petrópolis: Vozes, 1994.

CGI.br. Comitê Gestor da Internet no Brasil. Pesquisa sobre o uso das tecnologias de informação e comunicação nos domícilios brasileiros [on-line]: TIC domicílios 2015. São Paulo: Comitê Gestor da Internet no Brasil, 2016.

CIDADEBAIXA.COM. A Cidade Baixa Conectada com o Mundo. n. d. Disponível em:< http://www.cidadebaixa.com/>. Acesso em: 24 nov. 2017.

CLAVAL, P. Modes de Communication, Spatialités et Temporalités. In: RIO DE JANEIRO CONFERENCE: HISTORICAL DIMENSIONS OF THE RELATIONSHIP BETWEEN SPACE AND CULTURE, 1., Rio de Janeiro, 2003. Anais... Rio de Janeiro: International Geographical Union - Comission on the Cultural Approach in Geography, 2003, CD-ROM.

JUNQUEIRA, D. O que aconteceu com as lan-houses no Brasil? O Olhar Digital. 2012. Disponível em: <https://olhardigital.uol.com.br/noticia/lan-houses-ascasas-de-jogos-se-tornaram-centros-de-inclusao-digital/28528>. Acesso em: 28 maio 2017.

LEFEBVRE, Henri. O Direito à Cidade. São Paulo: Editora Moraes, 1991.

RIBEIRO, A. C. T. A atualização técnica do urbano. Cidades (Presidente Prudente), v. 5, n. 8, p. 189-213, 2008.

RISÉRIO, A. Uma história da cidade da Bahia. 2. ed. Rio de Janeiro: Versal, 2004.

SANTOS, M. A natureza do espaço. São Paulo: Hucitec, 1996.

. O espaço do cidadão. 2. ed. São Paulo: NOBEL, 1993.

SERPA, A. (Org.). Cidade popular: trama de relações socioespaciais. Salvador: Editora da Universidade Federal da Bahia - EDUFBA, 2007.

. Lugar e mídia. São Paulo: Contexto, 2011.

VASCONCELOS, H.; ANJOS, J. dos. 4 espaços públicos da cidade já dispõem de internet, mas pouca gente a utiliza. A Tarde, Salvador, p. A4, 8 jul. 2010.

Angelo Serpa - É doutor em Planejamento Paisagístico e Ambiental pela Universitaet Für Bodenkultur Wien, com Pós-Doutorado em Estudos de Organização do Espaço Exterior e Planejamento Urbano-Regional e Paisagístico realizado na Universidade de São Paulo, em Geografia Cultural e Urbana realizado na Université Paris IV (Sorbonne) e na Humboldt Universitätzu Berlin. Atualmente é professor titular da Universidade Federal da Bahia. 